\title{
Childhood Mortality Differentials by Ecological Region in Nepal
}

\begin{abstract}
Despite the rapid decline of childhood mortality in Nepal, there is considerable variation in the rate of progress by ecological region. Using the Nepal Demographic Health Survey (NDHS) 2011 data, we investigate two critical questions. First, whether the ecological differences in childhood mortality still remain independent of the factors known to influence mortality? Second, what socioeconomic and demographic factors shape these differences in childhood mortality across the ecological regions? The results from the Cox proportional hazard regression analysis, which controls for established socioeconomic and demographic factors known to influence childhood mortality, suggest that children who live in the hill and the Terai regions have a lower probability of death than those from the mountainous areas. The results of the Blinder-Oaxaca decomposition model further reveal that father's education, household economic status, place of residence, higher order births with lower birth interval, and mother's employment status significantly contribute to differences in childhood mortality across the ecological regions. Our findings provide important insights on the issue of (ecological) regional disparities in childhood mortality and draw attention to critical challenges for socioeconomic, population and health policy in Nepal.
\end{abstract}

Keywords: Childhood mortality; ecological regions; relative risk; decomposition;

Nepal

\section{INTRODUCTION}

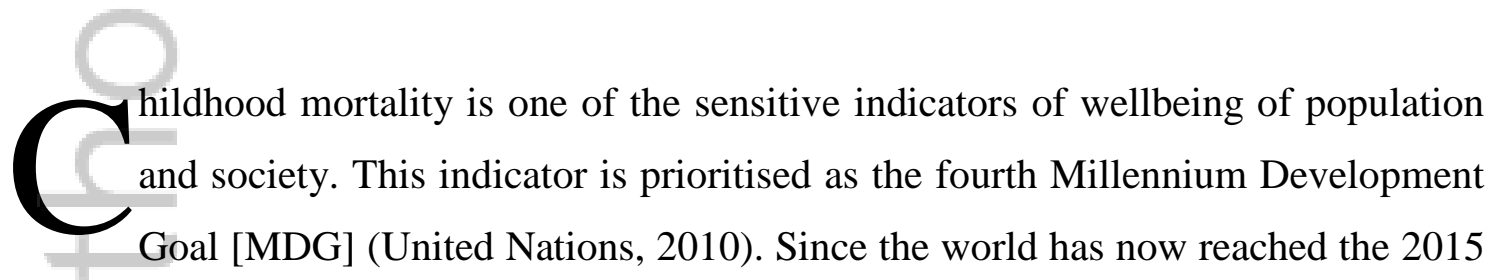
deadline, tracking progress towards achievement of the MDGs has intensified globally. This tracking reveals that while childhood mortality has declined worldwide, many countries are going to miss their target (Rajaratnam et al., 2010; Goli and Arokiasamy, 2014).

This is the author manuscript accepted for publication and has undergone full peer review but has not been through the copyediting, typesetting, pagination and proofreading process, which may lead to differences between this version and the Version of Record. Please cite this article as doi: 10.1002/PSP.1977 
In the case of Nepal, under-five (5q0) mortality declined from 118 per 1,000 live births in 1996 to 54 per 1,000 live births in 2011 (Pradhan et al., 1997; ICF International and PDMDP, 2011). Although the country has already achieved its original under-five mortality target of 54 deaths per 1,000 live births in 2011, a new target of 38 deaths per 1,000 live births was set for 2015 (Government of Nepal, 2013). While Nepal is on track to achieve the new target by the deadline, there is considerable variation in the rate of progress across ecological regions, typically divided into hill country, mountains, and Terai (ICF International and PDMDP, 2011; Government of Nepal, 2013). Moreover, Nepal's childhood mortality rates are still among the highest in the world (Chin et al., 2011). Furthermore, the country's mortality rate is in the bottom third of countries globally and is the fifth highest among South Asian countries (Uddin et al., 2009; Goli and Arokiasamy, 2014).

Childhood mortality is determined by various socioeconomic, demographic, health and environmental factors that operate at multiple levels- individual, household, community and region (Mosley and Chen, 1984). Specifically, child characteristics such as the age and sex of the child, place of residence, ethnicity, wealth, and maternal factors such as the mother's age, education, occupation, parity and birth interval are some of the important social-demographic factors documented globally (Hobcraft et al., 1984; Rutstein, 1984; Pradhan and Shrestha, 2005; Bennet et al., 2008; Bhandari et al., 2007; UNICEF Nepal, 2014; Goli et al., 2013). Studies have also reported environmental and bio-physical conditions and geographical barriers in the access to health care services and facilities and their utilisation (Caldwell, 1986; Wang, 2003; Mahy, 2003; Aggarwal et al., 2003; Mishra, 2007; Bhusal et al., 2009; Adhikari and Podhisita, 2010; UNICEF Nepal, 2014).

In Nepal, socioeconomic, demographic and geographical inequalities in the availability, accessibility and utilisation of health care facilities are some of the important contributors to the high prevalence of childhood mortality (Katz, 2003; Government of Nepal, 2013). In addition, there is considerable variation in childhood mortality across the three ecological regions. The recent Nepal demographic and health survey reported 58 under-five deaths per 1,000 live births in the hills, compared to 62 
deaths per 1,000 live births in the Terai. The mountainous region has the highest rate, with 87 under-five deaths per 1,000 live births (ICF International and PDMDP, 2011). A systematic investigation of the existing variations in childhood mortality rates across the three ecological regions and the factors contributing to these differences is necessary. The aim of this paper is to address this gap by answering two high priority scientific and policy questions. First, are existing ecological differences in childhood mortality independent of other factors known to influence mortality? And, second, what socioeconomic and demographic factors shape differences in childhood mortality across the three ecological regions of Nepal? With these investigations, this study offers new insights on socioeconomic and population policies concerning equity in the wellbeing of population and society across geographic space — the three ecological regions of Nepal.

\section{BACKGROUND}

Geographically, Nepal comprises three ecological regions: mountains, hills and the Terai. These regions run parallel from east to west (Figure 1). Significant variations exist among these three ecological regions in terms of climate, biogeography, resources, infrastructure and socioeconomic development (Upadhyaya, 2010). Historically, there is wide disparity in the socioeconomic wellbeing of the population in these three ecological regions (Thapa and Thapa, 1969; NESAC, 1998; Asian Development Bank, 2002; Bhandari et al., 2007; Government of Nepal, 2012; Nawal and Goli, 2013b). The mountain region accounts for $35 \%$ of the total land area, ranges in altitude from 4,877 meters to 8,848 meters above sea level and covers a land area of 51,817 square kilometers. Approximately $7 \%$ of the total population lives in this region (Government of Nepal, 2013). This region is less developed compared to the hill areas and the Terai due to its rugged terrain, poor agriculture and the lack of industrial production potential. Moreover, basic facilities such as transportation, education, communication, drinking water, sanitation, and electricity are less developed compared to the hill and Terai regions (Asian Development Bank, 2002; Government of Nepal, 2012). 
The hill region, which ranges in altitude from 610 meters to 4,876 meters above sea level, is densely populated. About $43 \%$ of the total population lives in the hill region. This region occupies about $42 \%$ of the total land area and includes the Kathmandu Valley - the capital city. Although the terrain is rugged and uneven, because of the high concentration of people and geopolitical reasons, this region has always received significant attention from the central government (Shrestha, 2001). As a result, this region has better access to basic facilities such as transportation, education, communication, drinking water, sanitation, electricity and health care facilities than that of the mountain region (Thapa and Thapa, 1969; Shrestha, 2001; Government of Nepal, 2012).

The Terai region in the southern plain has a subtropical to tropical climate and covers 23\% (34,019 square kilometers) of Nepal. The Terai region has the most fertile land in the country and is thus known as "the granary" (Gurung, 1998). While the Terai is only a quarter of the total land area, about $50 \%$ of the population lives here (Government of Nepal, 2012). Due to its relatively flat terrain, transportation and communication facilities, and other infrastructure, this region is well developed compared to the other regions. This region also receives significant attention from the central government (Government of Nepal, 2012; ICF International and PDMDP, 2011).

The recent Nepal Living Standards Survey [NLSS] reported that the mountain region is vulnerable to poverty (Government of Nepal, 2012). People living in the mountain areas have relatively limited access to modern health care facilities and most children do not receive both basic health care services, or treatment when they become ill (NESAC, 1998; Bhusal et al., 2009). Given this background, we expect that the existing variation in childhood mortality across the three ecological regions of Nepal is independent of various theoretically important socioeconomic and demographic factors. Further, from a policy perspective, socioeconomic and demographic factors through which child survival differences originate are important for making strategies to bring regional equity in it. 


\section{DATA AND METHODS}

We used data from the Nepal demographic health survey collected in 2010-11. Of particular interest to this study, the DHS data contains detailed information on mortality, maternal and child health, other socio-demographic characteristics, household assets by the three ecological regions (mountain, hill and Terai).

The survey used multi-stage cluster sampling to select a nationally representative sample of households and women (for details refer to ICF International and PDMDP, 2011). Altogether, 10,826 households were selected which yielded completed interviews of 12,674 women aged 15-49 years. In this study, we analysed 11,192 live birth cases reported by women.

The analysis was conducted in four stages. First, descriptive statistics such as proportions were calculated to show the distribution of sample across the categories of the variables used in this study. Second, under-five childhood mortality rates were estimated by using the Life-Table approach. These results were disaggregated by place of residence, sex of the child and wealth quintiles in all three ecological regions. Third, adjusted effects of ecological regions on childhood mortality rates were estimated by using Cox proportional hazard regression (Cox and Oakes 1984). Fourth, we decomposed the differences in childhood mortality between the disadvantaged mountain region and advantageous hill and Terai regions by employing a linear Blinder-Oaxaca decomposition model (Oaxaca 1973; Blinder 1973). Below we briefly describe Cox proportional hazard regression estimation technique and the Blinder-Oaxaca decomposition model.

\section{Cox Proportional Hazard Regression Model Estimation}

The Cox proportional hazard regression model was used to estimate the differences in childhood mortality, measured as under-five mortality, by ecological regions after 
controlling for socioeconomic and demographic factors. Mathematically, the Cox proportional hazard regression is expressed as:

$$
h(t, X)=h_{0}(t) \exp \left(\beta_{1} X_{1}+\beta_{2} X_{2} \ldots \cdots \cdots \cdots \cdots \cdots \beta_{\mathrm{k}} X_{\mathrm{k}}\right)
$$

$\mathrm{X}_{i}$ stands for covariates or explanatory variables used in the model. The quantity $h_{0}(\mathrm{t})$ is the baseline or an underlying hazard function and corresponds to the probability of dying when all explanatory variables are zero. The regression coefficients $\beta_{s}$ are the proportional changes in the hazards due to changes in the explanatory variables.

The Cox proportional hazard regression assumes that the hazard of childhood death at time ' $\mathrm{t}$ ' (e.g. age) of a child in the mountain region (z) is proportional to the hazard of childhood death with combined hill and Terai regions (y) by the same factor $\psi$ at time t. Mathematically, it is expressed as:

$$
h_{z}(t)=\psi h_{y}(\mathrm{t})
$$

Where, $h_{z}$ and $h_{y}$ are the hazards (probabilities of childhood deaths) for the two groups of children, mountain vs. hill and mountain vs. Terai respectively, and $\psi$ is the hazard ratio. Hazard ratio is interpreted as, if $\psi>1$, the hazard of childhood deaths is larger for children living in the mountain region than for children who are living in the hill and Terai regions. On the other hand, if $\psi<1$, the hazard of childhood deaths is smaller for children living in the mountain region compared to those who are living in hill and Terai regions. Similarly, if $\psi=1$, there is no difference in the hazard of childhood deaths of children living in the mountains compared to those who are living in the hill and Terai regions.

\section{Blinder-Oaxaca Decomposition Model}

Blinder-Oaxaca's linear decomposition model was used to decompose the contribution of various factors to under-five childhood mortality (Oaxaca, 1973, Blinder, 1973). As this method is appropriate for binary outcome variables, we computed a binary variable of ecological regions as disadvantageous mountain region (coded 1) and advantageous 
hill and Terai regions combined (coded 0). Our outcome variable is y, under-five mortality. Then, the gap between the mean outcomes is:

$$
\begin{aligned}
& y^{\text {mountain }} \text { and } y^{\text {hill and Terai }}= \\
& y^{\text {mountain }}-y^{\text {hill and Terai }}=\beta^{\text {mountain }} x^{\text {mountain }}-\beta^{\text {hill and Terai }} x^{\text {hill and Terai }}
\end{aligned}
$$

Where, $x^{\text {mountain }}$ and $x^{\text {hill and Terai }}$ are vectors of explanatory variables evaluated at the means of mountain, and combined hill and Terai, respectively.

Further, we estimated how much of the overall gap or the gap specific to any one of the Xs is attributable to 1) differences in Xs (also called the explained component) and 2) differences in $\beta$ s (also called the unexplained component). Mathematically, it is expressed as:

$$
y^{\text {mountain }}-y^{\text {hill and Tarai }}=\Delta x \beta^{\text {mountain }}+\Delta \beta x^{\text {hill }}
$$

Where, $\Delta x=x^{\text {hill }}-x^{\text {mountain }}$ (explained component) and $\Delta \beta=\beta^{\text {hill }}-\beta^{\text {mountain }}$ (unexplained component).

\section{Variables}

\begin{tabular}{|c|c|}
\hline Variables & Definition/measures and recoding \\
\hline \multicolumn{2}{|c|}{ Dependent variable (Outcome measure) } \\
\hline $\begin{array}{l}\text { Under-five mortality } \\
\left({ }_{5} \mathrm{q}_{0}\right)\end{array}$ & $\begin{array}{l}\text { Under-five mortality is defined as the probability of dying before the } \\
\text { fifth birthday (between 0-59 months). Under-five mortality was } \\
\text { recoded as Yes (coded 1) if any death occurred before the fifth birthday } \\
\text { ( } 0 \text {-59 months), otherwise No (coded } 0 \text { ). }\end{array}$ \\
\hline \multicolumn{2}{|l|}{ Predictor variables } \\
\hline Ecological region & $\begin{array}{l}\text { Ecological region has three categories - mountain, hill and Terai. As } \\
\text { the mountain region is considered to be the most disadvantaged region, } \\
\text { this region was used as the reference category. }\end{array}$ \\
\hline & \\
\hline Mother's and father's & Education of both mother and father was categorised as - no education, \\
\hline
\end{tabular}

Definition and coding of key variables used in the analysis are provided in Table 1.

Table 1. Definition of variables/measures and their recoding 


\begin{tabular}{|c|c|}
\hline education & $\begin{array}{l}\text { primary education, and secondary or higher education. Mothers or } \\
\text { fathers with no education were considered as the reference category. }\end{array}$ \\
\hline Wealth c & $\begin{array}{l}\text { Household economic status (wealth quintile) was measured based on } \\
\text { the mean of the } 33 \text { household assets and housing characteristics. Each }\end{array}$ \\
\hline & $\begin{array}{l}\text { of the household assets was assigned a weight (factor score) generated } \\
\text { through principle component analysis, and the resulting asset scores } \\
\text { were standardized in relation to normal distribution with mean of zero }\end{array}$ \\
\hline & and standard deviation of one. Then, the sample was divided into five \\
\hline & $\begin{array}{l}\text { iddle, richer and richest. Poorest category } \\
\text { ace category. }\end{array}$ \\
\hline & $\begin{array}{l}\text { Mother's religion was categorised as Hindu, Buddhist, and others. } \\
\text { Hindu religion was considered as the reference category. }\end{array}$ \\
\hline $\begin{array}{l}\text { Mother's autonomy } \\
\text { (freedom to take } \\
\text { decision on health care) }\end{array}$ & $\begin{array}{l}\text { In the survey, mother's autonomy about freedom to take decisions on } \\
\text { health care was measured in six categories: respondent alone, } \\
\text { respondent along with husband, respondent along with other family } \\
\text { members, husband/partner alone, and someone else. For analysis, this } \\
\text { variable was recoded into two categories - whether a mother reported } \\
\text { that she had freedom to take decision on health care alone or along } \\
\text { with others (Yes }=1) \text {, otherwise }(\mathrm{No}=0) \text {. }\end{array}$ \\
\hline $\begin{array}{l}\text { Mother's current work } \\
\text { status }\end{array}$ & $\begin{array}{l}\text { Measured as whether a mother was currently working (Yes=1), } \\
\text { otherwise }(\mathrm{No}=0) \text {. }\end{array}$ \\
\hline Mass media exposure & $\begin{array}{l}\text { Computed based on mother's exposure to television, radio, and } \\
\text { newspapers. This measure is recoded as exposed to any mass media } \\
\text { (Yes }=1 \text { ), otherwise }\left(\mathrm{No}_{0}=0\right) \text {. }\end{array}$ \\
\hline $\begin{array}{l}\text { Mother's age at birth of } \\
\text { first child }\end{array}$ & $\begin{array}{l}\text { Mother's age at birth of first child was recoded into three categories - } \\
\text { less than } 20 \text { years (used as a reference category), 21-29 years and } 30 \\
\text { years or more. }\end{array}$ \\
\hline $\begin{array}{l}\text { Birth order and birth } \\
\text { interval combinations }\end{array}$ & $\begin{array}{l}\text { Birth order and birth interval were combined as (a) birth order } 1 \text {, (b) } \\
\text { birth order } 2-3 \text { and }<=24 \text { months of interval, (c) birth order } 2-3 \text { and } \\
>24 \text { months of interval, (d) birth order } 3+\text { and }<=24 \text { months of interval, }\end{array}$ \\
\hline & $\begin{array}{l}\text { and (e) order } 3+\text { and }>24 \text { months of interval. Birth order } 1 \text { is } \\
\text { considered as the reference category. }\end{array}$ \\
\hline
\end{tabular}

Further, as suggested in a Blinder-Oaxaca linear decomposition model (Oaxaca, 1973), we dichotomised socioeconomic and demographic variables to perform the differential decomposition analyses. For example, a child's sex as male or female, place of residence as rural or urban, education of parents as no education or with education, economic status as poor or non-poor, working status as working or not working, mass media exposure as exposed or not exposed, and freedom to take decision on health care as yes or no, age at first birth as risky age ( $<20$ years and $>30$ years) or non-risky age 
(20-29 years), combinations of birth order and birth intervals with order $3+$ and $<=24$ months included in one category with code 1 and others as coded 0.

\section{RESULTS}

Table 2 provides descriptive statistics of all the variables used in this study. This study utilized information from a total of 11,192 children born in the past ten years $(52 \%$ male; $48 \%$ female). About 32\% were first order births, $12 \%$ were born in birth orders 2 and 3 with less than 24 months of birth interval, and $17 \%$ belonged to $3+$ birth orders with a birth interval of more than 24 months. Of all live births in the past ten year's birth history of a woman, 5.8\% of the children died before reaching their fifth birthday.

Only $8 \%$ of the children were from the mountain region as compared to $40 \%$ from the hill and 52\% from the Terai regions. Around 22\% of the mothers reported that they were below age 20 at the time their first child was born. Sixty percent of mothers were between the ages of 20-29 and 18\% were 30 years and above.

Literacy in Nepal is low (Government of Nepal, 2012) with female illiteracy as high as $53 \%$ of mothers compared to $25 \%$ of fathers. Thirty three percent of mothers in the sample were not working. Mass media exposure was reasonably high. Around $87 \%$ of the mothers reported that they were exposed to mass media. Sixty three percent of mothers reported that they had freedom to take decisions regarding health care. Nearly half $(48 \%)$ of the children lived in poor households and $90 \%$ of them were from rural areas.

\section{Under-five Mortality Rates by Ecological Regions}

Table 3 shows under-five mortality rates by selected variables- sex of the child, ruralurban residence and household economic status separately for the three ecological regions. The results suggest that under-five mortality rates are consistently higher in the mountain region as compared to the hill and the Terai across selected socioeconomic characteristics (viz. gender, wealth quintile and rural areas) except in urban areas. 
In Table 4, we provide results of Cox proportional hazard regression that examined the differences in under-five mortality rates among ecological regions adjusting for the effects of other potential confounders. The results are provided in two models. Model 1 provides the bivariate association between under-five mortality and ecological regions. In Model 2, we provide the results of the associations between under-five mortality and ecological regions adjusting for the effects of other socioeconomic and demographic characteristics known to influence childhood mortality.

The unadjusted results in Model 1 show that the hazard ratio for under-five deaths is significantly lower in the hill (hazard ratio= 0.703; $\mathrm{p}<0.01$ ) and in the Terai (hazard ratio $=0.734 ; \mathrm{p}<0.01)$ regions as compared to the mountain region. Specifically, the findings imply that the probability of dying of children living in the hill and the Terai regions was $30 \%$ and $27 \%$, respectively, lower than those children who were living in the mountain region. The results in Model 2 further suggest that these differences still remain and are statistically significant (hill: hazard ratio $=0.762 ; \mathrm{p}<0.01 ;$ Terai: hazard ratio $=0.786 ; \mathrm{p}<0.05)$ even after controlling for various socioeconomic and demographic factors. Interpreted differently, the relative risk of experiencing a death under age five is considerably higher in the mountain region as compared to the hill and the Terai regions net of all other socioeconomic and demographic factors. There was only a small change in the hazard ratios even after controlling for these confounders suggesting us a strong and independent effect of the ecological region on under-five mortality. These results provide evidence that despite the faster decline in childhood mortality rates in Nepal, there is a wide gap in the rate of childhood mortality reduction among the three ecological regions.

The results of other confounders are equally important for discussion. The results suggest that children living in rural areas of Nepal (hazard ratio $=1.269 ; \mathrm{p}<=.05$ ) experienced much higher childhood mortality rates as compared to those who were living in urban areas. For instance, net of other factors, the children living in rural areas were $27 \%$ more likely to experience death before their fifth birthday than children living in urban areas. This could be because of the relatively better access to health facilities in urban areas than in rural areas. 
A child's gender did not significantly contribute to under-five mortality differentials. Birth order and birth interval, by contrast, were significant predictors of childhood mortality. The risk of death of a child whose birth order was second or third and was born with more than a 24 month interval was significantly lower (hazard ratio $=0.664$; $\mathrm{p}<=.01)$ than those who were first-born. On the other hand, the risk of death of a child whose birth order was third or higher and was born with less than a 24 month interval was significantly higher (hazard ratio $=1.383 ; \mathrm{p}<=.05$ ) than those who were first-born. Interestingly, mother's education did not contribute in a statistically significant way to childhood mortality in Nepal. This may be because of the small proportion of literate females in the group of 15-49 years (Government of Nepal, 2012). However, father's education did matter. The risk of death of a child was much lower if child's father was educated compared to a child whose father was not educated. This finding is salient in the patriarchal context of Nepal where most decisions are made by males. Mothers' working status and their freedom to make decisions about health care also significantly lowered the risk of child death. In addition, the risk of dying among children living in wealthier households was significantly lower than those who were living in the poorest households. However, under-five mortality was not significantly associated with mother's age at first birth, mass media exposure and their religion.

\section{Decomposition Analysis}

Table 5 presents the results of the Blinder-Oaxaca decomposition analysis. It shows the relative proportional contributions of selected socioeconomic and demographic factors to under-five mortality differences between the mountain and the hill/Terai regions of Nepal. The socioeconomic and demographic predictors explained about $40 \%$ of the total under-five mortality differences between the mountain and the combined hill/Terai. The remaining $60 \%$ constituted the unexplained residual component.

The decomposition results show that $34 \%$ of the mountain and the combined hill/Terai regional differences in under-five mortality were contributed by parental education. Father's education alone contributed to $30 \%$ of the variation. Further, 
household's economic status contributed about $25 \%$ of the ecological regional variation in under-five mortality. Among other factors, rural-urban place of residence (16\%) and birth order of third or higher with less than a 24 month birth interval $(11 \%)$ contributed significantly to the mortality differences across the ecological regions. The working status of the mother contributed only $5 \%$ of under-five mortality difference between the regions. Other predictors such as mother's freedom to take decision on health care (3\%), religion (3\%) and mother's mass media exposure also contributed a small fraction of under-five mortality differences. The negative contribution $(-0.01 \%)$ of male child indicated that the female child was in a disadvantageous position in terms of under-five mortality in Nepal. However, the difference was not statistically significant.

\section{DISCUSSION}

In this paper, we present an empirical assessment of the relevance of type of ecological regions on child survival in Nepal and suggest a number of intriguing findings of wider policy relevance. Our findings indicate that among the three ecological regions, the children in the mountain region have a higher risk of mortality before their fifth birthday compared to those living in the hill and the Terai regions. The same pattern holds even after controlling for various socioeconomic and demographic characteristics. Among other factors, fathers' education, mothers' work status, her role in decision making regarding health care, birth order and birth interval and household economic status also emerged as significant predictors of childhood mortality in Nepal.

While evidence suggests a significant variation in childhood mortality by ecological regions, understanding of specific factors contributing to such variation is important. The decomposition analysis revealed that socioeconomic and demographic factors together explained about $40 \%$ of the difference in under-five mortality between the mountain and the combined hill/Terai regions. The results show that father's education $(30 \%)$ is the largest contributor to the under-five mortality difference between two 
regions, mountain and hill/Terai, which is followed by household economic status $(24.5 \%)$ and place of residence $(15.5 \%)$.

These findings draw attention to crucial issues responsible for regional inequalities in societal wellbeing and resultant challenges for several socioeconomic and population policies in Nepal. First, this study provides evidence of the ecological regional inequality in childhood mortality in Nepal, which is an important area of policy focus. Second, we found that father's education, household's economic status, rural place of residence and higher order births in combination with low birth intervals were the important factors contributing to ecological differences in childhood mortality in Nepal. These findings are important from a policy perspective. A focus on interventions in the mountain region with a particular emphasis on improving parental education is crucial for minimizing the ecological regional gap in childhood mortality rates. In addition, improving the households' economic status may further improve child survival in the mountain region. Similarly, reduction of the rural-urban gap and improvement in birth spacing will also help in narrowing the regional gap in child mortality.

These results are consistent with the findings of the recent Nepal Living Standard Survey (Government of Nepal, 2012), which pointed towards a large developmental gap between the mountain and other two ecological regions. Other studies also documented marked differences in health care facilities and accessibility across the three ecological regions (e.g. Nawal and Goli, 2013a and 2013b; UNICEF Nepal, 2014). It is reported that only $37 \%$ of the households in the mountain region have access to health facilities within 30 minutes as compared to $76 \%$ households in the hill and the Terai regions which could have important implications on maternal and child health care utilisation and thereby childhood mortality rates across ecological regions (Government of Nepal, 2012). Likewise, the mountain region is in a demographically disadvantaged situation as compared to the hill and the Terai regions: high fertility rates, fewer safe deliveries, underweight babies and anaemia and poor immunization coverage among children contribute to the child survival gap between ecological regions.

In addition, the mountain region is populated largely by ethnically disadvantaged communities such as Sherpas (Thapa and Thapa, 1969; Shrestha, 2001). Previous 
studies revealed that willingness to use and pay for modern medical care among the people of mountain region is very low (Nawal and Goli, 2013a and 2003b). This region continues to receive less attention from the central government in terms of socioeconomic development, family welfare and health care investments. The crisis further deepened when both Maoist and government forces made it difficult for international organizations and non-governmental organizations to deliver services in the mountain region. The situation during the conflict was further aggravated in the mountains because of destruction of health care facilities and abduction of health care workers by the Maoists (Shrestha, 2001; Singh, 2004; Upadhyaya, 2010). On the other hand, the population living in the hill and Terai region have relatively better access to basic amenities, family planning and health care facilities, and have better living conditions. This may have resulted in better utilisation of health care facilities and thus have better health outcomes in these regions (Government of Nepal, 2012; ICF International and PDMDP, 2011).

Results from our decomposition analysis suggest that about $60 \%$ of the difference between the mountain area and the hill/Terai is not explained, which needs further attention. The unexplained part can be attributed to other factors such as environmental and physiographical concerns, access to health facilities, health care and child specific health measures (e.g. birth weight, birth size, place of delivery, antenatal and postnatal care, etc.). As mentioned earlier, we were not able to include these direct measures of environmental, physiographical and health care utilisation factors as these measures were not available in the data. Therefore, a detailed further investigation is needed to examine the effects of these factors on childhood mortality in Nepal. This is evidenced by our results that even among children of similar socioeconomic and demographic status and place of residence, mortality largely varied between the mountain area and the other two ecological regions. This hints at the role of other factors possibly related to environmental and physiographical conditions of the three ecological regions which may be equally important in explaining child survival. Previous studies support the argument that environmental and physiographic factors such as altitude, abnormal temperature and rainfall, and other environmental hazards have a significant effect on 
child health and survival (Katz, 2003; Mishra, 2007; Bhusal et al., 2009). The high altitude, climate and living conditions put mountain region in a disadvantageous position in terms of child survival. Although some of these factors are beyond human control, precautionary measures may help increase survival chances of children in environmentally unfavourable locations like the mountain region.

Furthermore, Nepal Demographic and Health Surveys do not collect information on health care facilities and their access. Information on antenatal and postnatal care was collected only for the last birth. Likewise, information regarding place of delivery, delivery care, birth size and birth weight were collected but there are a huge number of missing cases in these variables due to recall problems Hence results based on such variables may be biased.

In conclusion, despite the decline of childhood mortality in Nepal, our findings suggest that the challenge of childhood mortality in Nepal should be addressed from an ecological region perspective. Although there is no easy solution, it would be helpful to have a focus on the socioeconomic development of the disadvantageous mountain region with increased focus on parental education, mother's work, household economic condition and a reduction in the rural-urban gap through providing access to health care facilities may be helpful in addressing the challenge of high childhood mortality in this region. From a resource distribution and efficiency perspective, it seems unwise for policy makers to invest severely limited resources for only $7 \%$ of the sparsely scattered population in the mountain region. However, from a welfare perspective, it is important to allocate adequate resources in the mountain region for two reasons: 1) in order to achieve the new target of MDGs-4 in Nepal, the reduction of childhood mortality in this part of the country becomes very important. Unless we reduce childhood mortality in all the ecological regions, it is difficult to achieve the new target. 2) Nepal may achieve the MDG-4 target without considering the mountain region. However, the focus on the region is still important under the principles of right to health for all of the Alma Ata declaration of 1978 and the recent proposal of universal health coverage, and the post2015 MDG agenda of international public health policy. A focus on mobile health centers and emergency ambulance services may be an economically viable alternative to 
increase access to, and utilisation of, health care facilities in sparsely populated mountain regions. However, the focus should be on achieving greater socio-economic equity and wellbeing for the population as a whole in all the three ecological regions, and especially in the mountain areas.

\section{REFERENCES}

Aggarwal AK, Kumar R, Kumar P. 2003. Early neonatal mortality in hilly north Indian states: Socio-demographic factors and treatment seeking behaviour. Indian journal of preventive social medicine 34 (1-2): 46-58.

Adhikari R, Podhisita C. 2010. Household headship and child death: evidence from Nepal. BMC International Health and Human Rights 10, 13.

Asian Development Bank (2002). Poverty reduction in Nepal: Issues, findings, and approaches. http://www.adb.org/Documents/Reports/Poverty_Reduction_NEP/poverty_analysis.pdf (retrieved on September 20, 2005).

Bennet L, Dahal DR, Govindasamy P. 2008. Caste, Ethnic and Regional Identity in Nepal: Further Analysis of the 2006 Demographic and Health Surveys. Macro International Inc., Calverton, Maryland, USA.

Bhandari P, Shrestha SS, Dirgha JG. 2007. Sociocultural and Geographical Disparities in Child Immunization in Nepal. Asia-Pacific Population Journal, 22(2): 43-64.

Bhusal CL, Dhimal M, BhatTerai L. 2009. Situation Analysis of Environmental Health in Nepal, World Health Organisation, Nepal Health Research Council.

Blinder, A S. 1973. Wage Discrimination: Reduced Form and Structural Estimates. Journal of Human Resources 8 (4): 436-455.

Chhetri N, Chaudhary P, Tiwari PR., Yadaw RB. 2011. Institutional and technological innovation: Understanding agricultural adaptation to climate change in Nepal. Applied Geography 33 (2012): 142e150.

Chin B, Montana L, Basagana X. 2011. Spatial modelling of geographic inequalities in infant and child mortality across Nepal. Health \& Place 17: 929-936.

Caldwell J. 1986. Routes to low mortality in poor countries. Population and Development Review 12 (2): 171-220.

Cox D R, Oakes D. 1984. Analysis of Survival Data, London: Chapman \& Hall. 
Goli S, Arokiasamy P. 2014. Maternal and Child Mortality Indicators across 187 countries in the World: Converging or Diverging. Global Public Health: An International Journal for Research, Policy and Practice. 9(3):342-60

Goli S, Riddhi D, Arokiasamy P. 2013. Pathways of economic inequalities in maternal and child health in urban India: A decomposition analysis. PLOS One, 8 (3), e58573

Government of Nepal. 2012. Central Bureau of Statistics, National Planning Commission Secretariat. Available at http:// www.Central Bureau of Statistics.gov.np [Accessed 5 May 2011].

Government of Nepal. 2013. Nepal Millennium Development Goals. Progress Report. Government of Nepal. National Planning Commission Secretariat, Kathmandu, Nepal.

Gurung H. 1998. Nepal: social demography and expressions. New Era: Kathmandu.

Hobcraft JN, Mcdonald JW, Rutstien SO. 1984. Socioeconomic Factors in Infant and Child Mortality: A Cross-national Comparison. Population Studies 38 (2): 193-223.

ICF International and PDMDP. 2011. Nepal Demographic and health survey: New ERA and Macro International Inc: Calverton, Maryland, USA and Kathmandu, Nepal.

Katz J. 2003. Risk factors for early infant mortality in Sarlahi district, Nepal. Bulletin of the World Health Organization 81(10): 717-725.

Mahy M. 2003. Childhood mortality in the developing world: a review of evidence from the Demographic and Health Surveys (DHS Comparative Reports No. 4). Calverton, Maryland, USA.

Mishra RP. 2007. Geography of Health: A Treatise on Geography of Life and Death in India. Concept Publishing, New Delhi.

Mosley WH, Chen LC. 1984. An analytical framework for the study of child survival in developing countries. Population and Development Review 10: 25-45.

NESAC 1998. Nepal human development report 1998, Nepal South Asia Centre, Kathmandu, Nepal.

Nawal D, Goli S. 2013a. Birth Preparedness and Its Effect on Place of Delivery and Post-Natal Check-Ups in Nepal. PLoS ONE 8(5): e60957. doi:10.1371/journal.pone.0060957.

Nawal D, Goli S. 2013b. Inequality in Utilisation of Maternal Health Care Services in Nepal. Ethnicity and Inequalities in Health and Social g 3-15.

Oaxaca R. 1973. Male-Female Wage Differentials in Urban Labour Markets. International Economic Review 14: 693-709. 
Pradhan A, Ram H A, Gokarna R, Bharat B, Pavalavalli G. 1997. Nepal Family Health Survey 1996. Kathmandu, Nepal and Calverton, Maryland: Ministry of Health [Nepal], New ERA, and Macro International Inc.

Pradhan R, Shrestha A. 2005. Ethnic and caste diversity: Implications for development, Working Paper Series No. 4, Nepal Resident Mission, Asian Development Bank.

Rajaratnam J K, Marcus J R, Flaxman A, Wang H, Levin-Rector A, Dwyer L, Murray C J L. 2010. Neonatal, post neonatal, childhood, childhood and under-5 mortality for 187 countries, 1970-2010: Systematic analyses of progress towards millennium development goal 4. The Lancet, 375, 1988-2008.

Rutstein SO. 1984. Infant and Child Mortality: Levels, Trends and Demographic Differentials. World Fertility Survey Comparative Studies No 43.Cross-national Summaries. International Statistical Institute, Voorburg, Netherlands.

Singh S. 2004. Impact of long-term political conflict on population health in Nepal, Canadian Medical Association Journal 171 (12): 1499-1501.

Shrestha A. 2001. Bleeding Mountains of Nepal: a story of corruption greed and misuse of Power, Bloomington: iUniverse, incorporated.

Thapa NP, Thapa DP. 1969. Geography of Nepal: physical, economic, cultural and regional, Orient Longmans, Bombay, India.

UNICEF Nepal. 2014. Water, Sanitation and Hygiene Programme in Nepal. http://www.unicef.org/nepal/5522_WASH-Environmental_Sanitation_and_Hygiene.htm [Accessed 25 May 2014].

United Nations. 2010. The millennium development goals report, 2010. Retrieved from http:// www.un.org/millenniumgoals/pdf/report-2013/mdg-report-2013-english.pdf

Uddin Md, Zakir Hossain Md, Ohid Ullah Md. 2009. Child Mortality in a Developing Country: A Statistical Analysis. Journal of applied quantitative methods 4 (3): 270-283.

Upadhyaya SK. 2010. Upland Poverty in Nepal: the Role of Environment, Institute for Integrated Development Studies (IIDS), Nepal: Kathmandu.

Wang L. 2003. Determinants of child mortality in LDCs: empirical findings from demographic and health surveys. Health Policy 65: 277-299.

Figure 1. Ecological regions in Nepal 

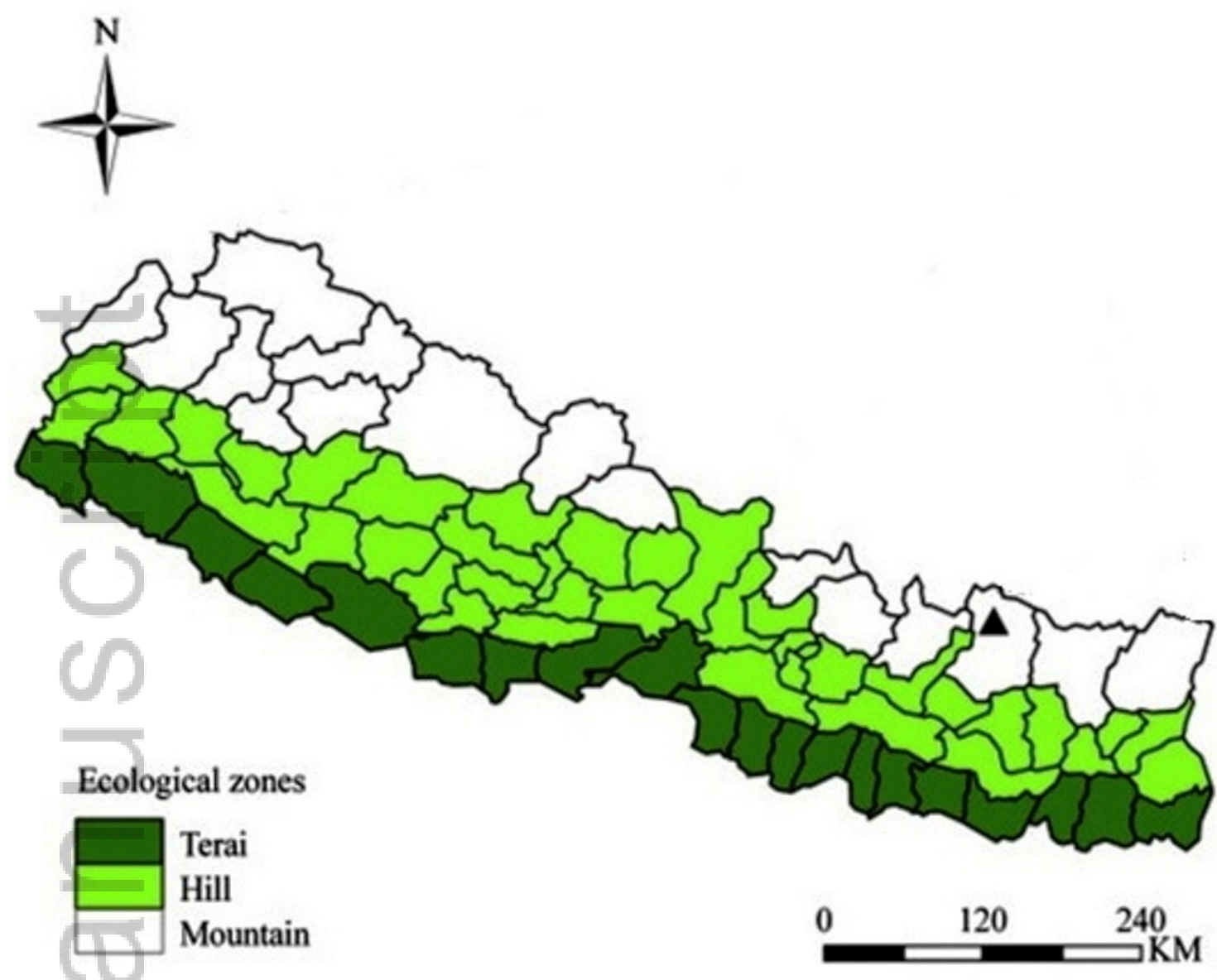

Source: Chhetri et al. (2011)

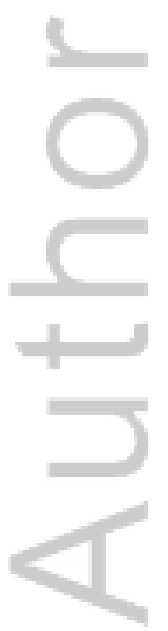

This article is protected by copyright. All rights reserved. 
Table 2 Descriptive statistics of variables, Nepal, $2011(\mathrm{~N}=11,192 \dagger)$.

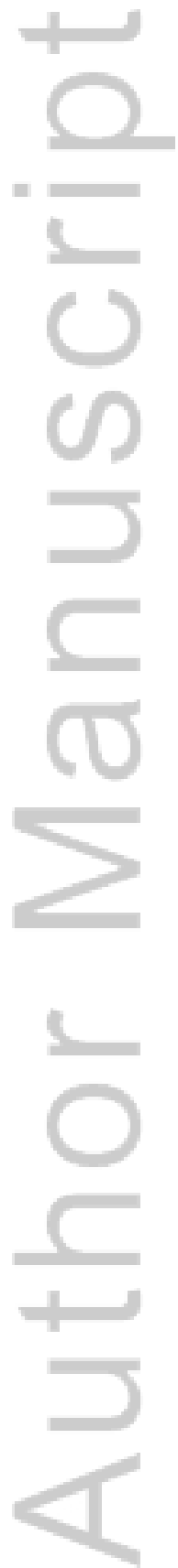

This article is protected by copyright. All rights reserved. 
Note: Proportions are weighted for differential probability of selecting the subsamples in multi-level sampling

\begin{tabular}{|c|c|c|}
\hline Measures & Value Labels & Proportione \\
\hline \multicolumn{3}{|l|}{ Outcome measure } \\
\hline Under-five deaths & Yes & 0.058 \\
\hline \multicolumn{3}{|l|}{ Predictors } \\
\hline \multirow{3}{*}{ Ecological regions } & Mountain & 0.080 \\
\hline & Hill & 0.397 \\
\hline & Terai & 0.523 \\
\hline \multicolumn{3}{|l|}{ Child characteristics } \\
\hline \multirow[t]{2}{*}{ Sex of child } & Male & 0.517 \\
\hline & Female & 0.483 \\
\hline \multirow{5}{*}{$\begin{array}{l}\text { Birth order and birth interval } \\
\text { combinations }\end{array}$} & Order 1 & 0.319 \\
\hline & Order $2-3$ and $<=24$ months & 0.118 \\
\hline & Order 2-3 and >24 months & 0.321 \\
\hline & Order $3+$ and $<=24$ months & 0.067 \\
\hline & Order $3+$ and $>24$ months & 0.174 \\
\hline \multicolumn{3}{|l|}{ Parental and household characteristics } \\
\hline \multirow[t]{3}{*}{ Mother's age at first birth of child } & Less than or equal to 19 & 0.219 \\
\hline & $20-29$ & 0.602 \\
\hline & More than equal to 30 & 0.179 \\
\hline \multirow[t]{3}{*}{ Mother's education } & No education & 0.525 \\
\hline & Primary & 0.200 \\
\hline & Secondary or higher & 0.275 \\
\hline \multirow{3}{*}{ Father's education } & No education & 0.250 \\
\hline & Primary & 0.257 \\
\hline & Secondary or higher & 0.493 \\
\hline \multirow[t]{2}{*}{ Mother's working status } & No & 0.333 \\
\hline & Yes & 0.667 \\
\hline \multirow[t]{2}{*}{ Mass media exposure } & No & 0.131 \\
\hline & Yes & 0.869 \\
\hline \multirow[t]{2}{*}{$\begin{array}{l}\text { Mother's freedom to take decision on } \\
\text { health care }\end{array}$} & No & 0.370 \\
\hline & Yes & 0.630 \\
\hline \multirow{3}{*}{ Religion } & Hindu & 0.848 \\
\hline & Buddhist & 0.080 \\
\hline & Others & 0.072 \\
\hline \multirow[t]{5}{*}{ Household wealth quintile } & Poorest & 0.262 \\
\hline & Poorer & 0.220 \\
\hline & Middle & 0.199 \\
\hline & Richer & 0.173 \\
\hline & Richest & 0.146 \\
\hline \multirow[t]{2}{*}{ Place of residence } & Urban & 0.102 \\
\hline & Rural & 0.898 \\
\hline
\end{tabular}


Table 3. Under-five mortality rate by socio-economic characteristics of child and place of residence by ecological regions, Nepal $2011(\mathrm{~N}=11,192)$.

\begin{tabular}{|c|c|c|c|c|c|c|}
\hline \multicolumn{7}{|c|}{ Under-five mortality rate $\left({ }_{5} \mathrm{q}_{0}\right)$} \\
\hline & \multicolumn{2}{|c|}{ Mountain } & \multicolumn{2}{|c|}{ Hill } & \multicolumn{2}{|c|}{ Terai } \\
\hline Characteristics & Means & S.E. & Means & S.E & Means & S.E \\
\hline \multicolumn{7}{|l|}{ Sex of the child } \\
\hline Male & $\begin{array}{c}87.7 \\
(71.6,107.2)\end{array}$ & 0.009 & $\begin{array}{c}59.9 \\
(50.5,70.8)\end{array}$ & 0.005 & $\begin{array}{c}58.3 \\
(49.3,68.9)\end{array}$ & 0.005 \\
\hline Female & $\begin{array}{c}79.4 \\
(63.8,98.7)\end{array}$ & 0.009 & $\begin{array}{c}58.7 \\
(49.1,70.1)\end{array}$ & 0.005 & $\begin{array}{c}63.5 \\
(53.6,75.1)\end{array}$ & 0.006 \\
\hline \multicolumn{7}{|c|}{ Place of residence } \\
\hline Urban & $\begin{array}{c}28.7 \\
(9.4,86.4)\end{array}$ & 0.016 & $\begin{array}{c}38.8 \\
(27.5,54.4)\end{array}$ & 0.007 & $\begin{array}{c}54.7 \\
(43.8,68.2)\end{array}$ & 0.006 \\
\hline Rural & $\begin{array}{c}86.6 \\
(74.5,100.5)\end{array}$ & 0.007 & $\begin{array}{c}64.4 \\
(56.4,73.4)\end{array}$ & 0.004 & $\begin{array}{c}63.6 \\
(55.2,73.2)\end{array}$ & 0.005 \\
\hline \multicolumn{7}{|c|}{ Household wealth quintile } \\
\hline Poorest & $\begin{array}{c}111.1 \\
(92.2,133.5)\end{array}$ & 0.011 & $\begin{array}{c}70.8 \\
(59.9,83.6)\end{array}$ & 0.006 & $\begin{array}{c}59.9 \\
(41.3,86.4)\end{array}$ & 0.011 \\
\hline Poorer & $\begin{array}{c}67.1 \\
(49.8,90.2)\end{array}$ & 0.010 & $\begin{array}{c}68.5 \\
(52.5,89.1)\end{array}$ & 0.009 & $\begin{array}{c}61.8 \\
(46.9,81.2)\end{array}$ & 0.009 \\
\hline Middle & $\begin{array}{c}44.1 \\
(26.2,73.6)\end{array}$ & 0.012 & $\begin{array}{c}34.9 \\
(22.1,54.8)\end{array}$ & 0.008 & $\begin{array}{c}76.3 \\
(61.0,95.3)\end{array}$ & 0.009 \\
\hline Richer & $\begin{array}{c}72.1 \\
(34.0,149.5)\end{array}$ & 0.027 & $\begin{array}{c}49.1 \\
(33.2,72.5)\end{array}$ & 0.010 & $\begin{array}{c}69.8 \\
(55.9,87.1)\end{array}$ & 0.008 \\
\hline Richest & $*$ & $*$ & $\begin{array}{c}38.7 \\
(25.2,59.2)\end{array}$ & 0.008 & $\begin{array}{c}37.3 \\
(50.8,27.4)\end{array}$ & 0.006 \\
\hline
\end{tabular}

Note: Figures in parenthesis indicate Confidence Intervals (CI) of under five mortality rates. *Figures are not shown because of less than 25 unweighted cases. 
Table 4. Cox proportional hazard model estimates (Hazard Ratios) for under-five deaths by selected predictors, Nepal $2011(\mathrm{~N}=11,192)$.

\begin{tabular}{|c|c|c|c|c|c|c|c|}
\hline \multirow[t]{3}{*}{ Measures } & & \multicolumn{3}{|c|}{ Model 1} & \multicolumn{3}{|c|}{ Model 2} \\
\hline & & \multirow[t]{2}{*}{$\begin{array}{c}\text { Hazard } \\
\text { Ratios }\end{array}$} & \multicolumn{2}{|c|}{$\begin{array}{c}95.0 \% \mathrm{CI} \text { for } \\
\operatorname{Exp}(\mathrm{B})\end{array}$} & \multirow[t]{2}{*}{$\begin{array}{c}\text { Hazard } \\
\text { Ratios }\end{array}$} & \multicolumn{2}{|c|}{ 95.0\% CI for $\operatorname{Exp}(B)$} \\
\hline & & & Lower & Upper & & Lower & Upper \\
\hline \multirow{2}{*}{$\begin{array}{l}\text { Ecological regions } \\
\text { (Ref= Mountain) }\end{array}$} & Hill & $0.703^{* *}$ & 0.577 & 0.856 & $0.762 * *$ & 0.620 & 0.938 \\
\hline & Terai & $0.734 * *$ & 0.604 & 0.892 & $0.786^{*}$ & 0.619 & 0.997 \\
\hline \multicolumn{8}{|l|}{ Child characteristics } \\
\hline Sex of child (ref=Male) & Female & - & - & - & 1.010 & 0.865 & 1.180 \\
\hline \multirow{5}{*}{$\begin{array}{l}\text { Birth order and birth } \\
\text { interval (months) } \\
\text { combination (ref=Birth } \\
\text { order 1) }\end{array}$} & & - & - & - & & & \\
\hline & Order $2-3$ and $<=24$ months & & & & 1.061 & 0.831 & 1.355 \\
\hline & Order 2-3 and >24 months & - & - & - & $0.664 * *$ & 0.524 & 0.841 \\
\hline & Order $3+$ and $<=24$ months & - & - & - & $1.383^{*}$ & 1.016 & 1.884 \\
\hline & Order $3+$ and $>24$ months & - & - & - & $0.610^{*}$ & 0.443 & 0.840 \\
\hline \multicolumn{8}{|c|}{ Parental and household characteristics } \\
\hline \multirow{2}{*}{$\begin{array}{l}\text { Age of at first birth } \\
(\mathrm{ref}=<=19)\end{array}$} & $20-29$ & - & - & - & 0.803 & 0.574 & 1.125 \\
\hline & $>=30$ & - & - & - & 1.018 & 0.597 & 1.738 \\
\hline \multirow[t]{2}{*}{$\begin{array}{l}\text { Mother's education (ref= } \\
\text { No education) }\end{array}$} & Primary & - & - & - & 1.155 & 0.930 & 1.436 \\
\hline & Secondary \& higher & - & - & - & 1.093 & 0.843 & 1.418 \\
\hline \multirow[t]{2}{*}{$\begin{array}{l}\text { Father's education (ref= } \\
\text { No education) }\end{array}$} & Primary & - & - & - & 0.873 & 0.611 & 1.246 \\
\hline & Secondary \& higher & - & - & - & $0.654^{*}$ & 0.443 & 0.967 \\
\hline $\begin{array}{l}\text { Mother's work status } \\
\text { (ref=not working) }\end{array}$ & Working & - & - & - & $0.623 * *$ & 0.516 & 0.751 \\
\hline $\begin{array}{l}\text { Mass media exposure } \\
(\mathrm{ref}=\mathrm{No})\end{array}$ & Yes & - & - & - & 0.858 & 0.693 & 1.063 \\
\hline $\begin{array}{l}\text { Mother's freedom to take } \\
\text { decision on health care } \\
\text { (ref=No) }\end{array}$ & Yes & - & - & - & $0.722 * *$ & 0.615 & 0.846 \\
\hline \multirow[t]{2}{*}{ Religion (ref=Hindu) } & Buddhist & - & - & - & 0.990 & 0.741 & 1.323 \\
\hline & Others & - & - & - & $0.705+$ & 0.507 & 0.979 \\
\hline \multirow{3}{*}{$\begin{array}{l}\text { Household wealth quintile } \\
\text { (ref=Poorest) }\end{array}$} & Poorer & - & - & - & $0.770^{*}$ & 0.619 & 0.770 \\
\hline & Middle & - & - & - & $0.748^{*}$ & 0.578 & 0.748 \\
\hline & Richer & - & - & - & $0.750+$ & 0.561 & 0.750 \\
\hline
\end{tabular}




\begin{tabular}{|c|c|c|c|c|c|c|c|}
\hline & Richest & - & - & - & $0.415 * *$ & 0.284 & 0.415 \\
\hline $\begin{array}{l}\text { Place of residence } \\
\text { (ref=Urban) }\end{array}$ & Rural & - & - & - & $1.269 *$ & 0.999 & 1.613 \\
\hline
\end{tabular}

Significance levels: $* * \mathrm{p}<0.01 ; * \mathrm{p}<0.05 ;+\mathrm{p}<0.1$; S.E.: Standard error of the estimate; ref $=$ reference category

\section{Summary of Oaxaca decomposition}

Mountain

Hill \& Terai

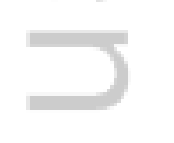

Difference

Explained

Unexplained

$\%$ Explained

$\%$ Unexplained (Residual)

Coefficient

$0.0805 * * *$

$0.0561 * * *$

$0.0245 * * *$

0.0098

$0.0147 * * *$

40.2

59.8

Details of explained part

Explanatory Factors

$\%$ Contribution

to total

\section{Child characteristics}

Sex of the child

Male

difference

Standard error

Birth order and birth interval combinations

Order $3+$ and

$<=24$ months

$-0.01$

0.0000

\section{Parental and household characteristics}

Mother's age at birth

Mother's education

Father's education

Mother's work status

Mother's media exposure

Mother's freedom to take decision on health care

Religion
$<20$ years

No education

1.8

0.0002

No education

4.4

$30.0 * *$

No 5.4*

0.9

3.2

3.2

No

No

.2

0.0010

0.0002

Hindu

0.0002

0.0002

0.0002
0.0858

0.0624

0.0328

0.0109

0.0164

$1.1 * * *$

0.0003 


\begin{tabular}{llll}
\hline Household wealth status & Poor & $24.5^{*}$ & 0.0005 \\
Place of residence & Rural & $15.5^{*}$ & 0.0006 \\
Total explained part & & 100.0 & \\
\hline
\end{tabular}

Table 5. Oaxaca decomposition: Contribution of selected predictors on under-five mortality difference between Mountain and Other (Hill and Terai) regions, Nepal 2011. Significance levels: *** $\mathrm{p}<0.01 ; * * \mathrm{p}<0.05 ; * \mathrm{p}<0.1$

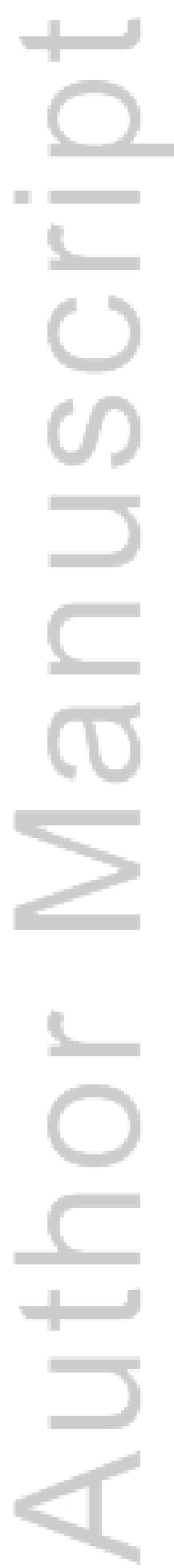

This article is protected by copyright. All rights reserved. 
Title: Childhood Mortality Differentials by Ecological Regions of Nepal

First Author (Corresponding author): Srinivas Goli, $\mathrm{PhD}$,

Assistant Professor, Population Studies

Centre for the Study of Regional Development (CSRD)

School of Social Sciences (SSS)

Jawaharlal Nehru University (JNU)

Phone No: 01126738798

Email: srinivasgoli@mail.jnu.ac.in; sirispeaks2u@gmail.com

(1)

Second Author: Prem Bhandari, $\mathrm{PhD}$, Assistant Research Scientist

Population Studies Center, Institute for Social Research

University of Michigan

426 Thompson Street, Ann Arbor, MI 4810

Phone: 734-469-6349

Email:prembh@umich.edu

Third Author: Uma Maheswara rao Atla, Research Analyst

HSUI Unit,G-Wing, National Building Organisation (NBO)

Ministry of Housing and Urban Poverty Alleviation (MoHUPA),

New Delhi-110011

Phone No: +91 8106597289

Email:atlamahesh@gmail.com

Fourth Author: Aparajita Chattopadhayay, PhD, Assistant Professor

Department of Development Studies

International Institute for Population Sciences

Govandi Station Road, Deonar, Mumbai-400088

Phone No: +919930909174

Email:apchat@rediffmail.com

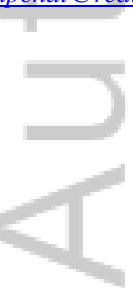

